\title{
Gastropulmonary fistula after bariatric surgery
}

\author{
Maya Doumit MD, Gaby Doumit MD MSc FRCSC, Farid M Shamji MBBS FRCSC FACS, \\ Sylvie Gregoire MD FRCPC, Richard E Seppala MD
}

\begin{abstract}
M Doumit, G Doumit, FM Shamji, S Gregoire, RE Seppala. Gastropulmonary fistula after bariatric surgery. Can J Gastroenterol 2009;23(3):215-216.

The Roux-en-Y gastric bypass is one of the most common operations for morbid obesity. Although rare, gastropulmonary fistulas are an important complication of this procedure. There is only one recently reported case of this complication. The present report describes the serious nature of this complication in a patient after an uneventful laparoscopic gastric bypass surgery.
\end{abstract}

Key Words: Argon plasma coagulation; Gastropulmonary fistula; Roux-en-Y gastric bypass; Tiessel fibrin glue

T aparoscopic Roux-en-Y gastric bypass surgery has now Lecome the standard operation for morbid obesity and has an acceptable success rate. However, the procedure is not without attendant complications, namely, wound complications including infection and hernia (1).

In contrast, the open approach for gastric bypass carries a higher risk of cardiopulmonary complications, wound infection, late incisional hernia and gastrojejunal anastomotic leak (2). A laparoscopic approach has the advantage of reduced morbidity and recovery time (3).

One serious and rare complication of this operation is the formation of a fistula between the stomach and lung. Aspiration pneumonitis develops and evolves into lung abscess formation with the attendant risk of life-threatening massive hemoptysis, bronchiectasis and recurrent local infection, pyopneumothorax and empyema. There is only one recently reported case (4) of this complication after gastric bypass surgery. However, it is not an unrecognized complication of esophagectomy and reconstruction using gastric conduit (5-12).

The present report describes the serious nature of this complication in a patient after an uneventful laparoscopic gastric bypass surgery.

\section{CASE PRESENTATION}

In December 2003, a 47-year-old woman with morbid obesity underwent laparoscopic small gastric pouch stapling and Roux-en-Y gastrojejunal bypass. After discharge from the hospital, she developed new-onset mid back pain and was treated with a nonsteroidal anti-inflammatory drug (NSAID). This resulted in an an upper gastrointestinal bleed secondary to NSAID-induced gastric ulceration.

Three months after the operation, urgent admission was necessary for the management of acute pulmonary sepsis following the patient's complaints of cough with purulent sputum, fever and choking on drinking liquids. A computed tomography (CT) chest scan demonstrated a left lower lobe lung abscess. A contrast study of the esophagus and stomach demonstrated a transdiaphragmatic fistulous connection between the gastric pouch and the lower lobe of the left lung (Figure 1).

\section{Une fistule gastropulmonaire après une chirurgie bariatrique}

La dérivation gastrique Roux-en-Y est l'une des principales interventions de l'obésité morbide. Bien qu'elles soient rares, les fistules gastropulmonaires en constituent une complication importante. Un seul cas de cette complication a été déclaré récemment. Le présent rapport décrit la gravité de cette complication chez un patient après une dérivation gastrique par laparoscopie, effectuée sans incident.

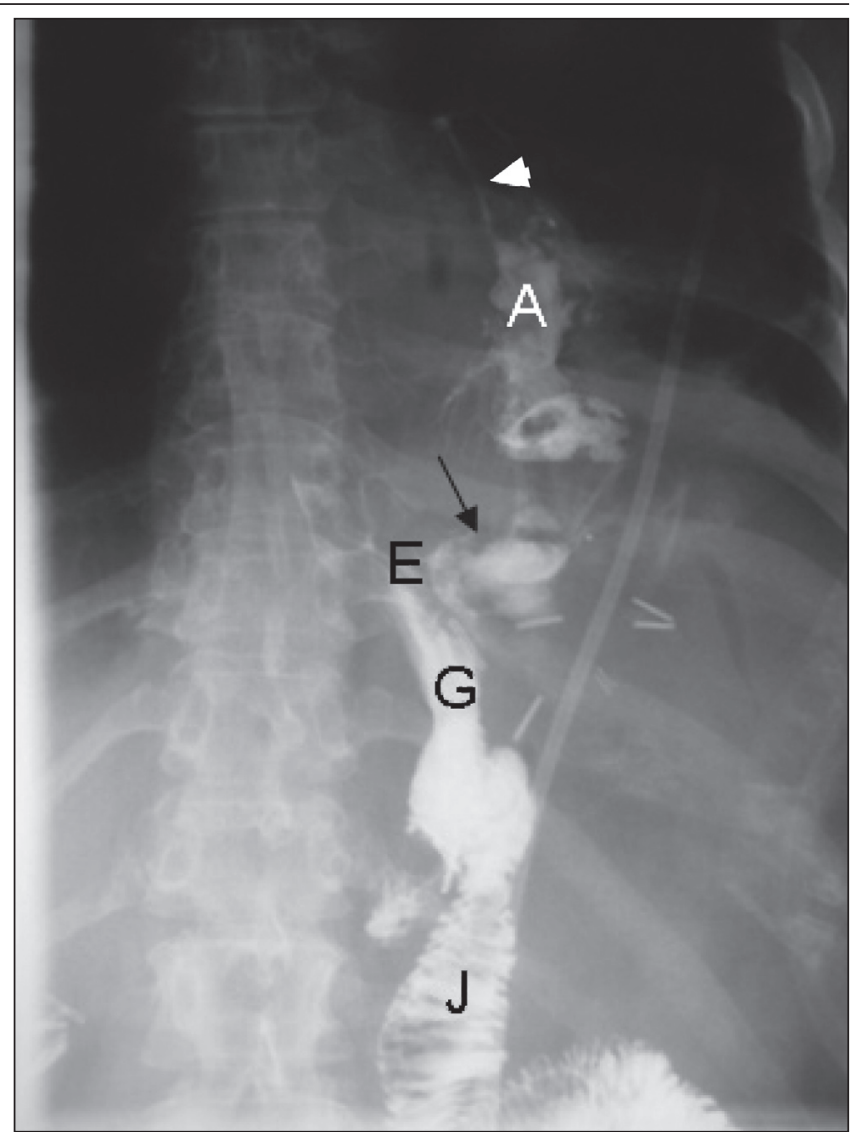

Figure 1) Chest $x$-ray with contrast study of the esophagus (E) and stomach demonstrating a transdiaphragmatic fistulous connection between the gastric pouch $(\mathrm{G})$ and the lower lobe of the left lung. The arrowhead indicates contrast of the left lobe bronchus, and the arrow indicates leak from the gastric remnant. A Abscess in the left lower lobe; J Jejunum

An urgent laparotomy was performed for repair of the fistula and for revision of the gastrojejunal anastomosis. An

Department of General Surgery, Ottawa Hospital, Ottawa, Ontario

Correspondence: Dr Maya Doumit, Department of Genral Surgery, Ottawa Hospital, 2096 Lamira Street, Ottawa, Ontario K1H 1 N8.

Telephone 613-797-0012, fax 613-232-8100, e-mail mayadoumit@hotmail.com

Received for publication June 6, 2008. Accepted August 1, 2008 
inflammatory phlegmon was found in the left upper abdomen. The lung abscess was treated with percutaneous drainage. However, it did not resolve and open thoracotomy drainage was necessary. Thereafter, there was clinical and radiological improvement, and repeat contrast study two months after the operation demonstrated a contained leak from the gastric pouch without fistulization.

Within 10 days of discharge, the fistula recurred and was confirmed on contrast study. Management now consisted of advice for complete cessation of oral intake, total parenteral nutrition and intravenous antibiotics.

After two months of conservative treatment, left thoracotomy for repair of the persistent fistula was necessary. In spite of omental transfer, fistula closure was not achieved and conservative treatment was resumed. However, throughout this time, the patient had continued to eat against medical advice.

One month later, an attempt was made to close the pulmonary end of the fistula with the insertion of gel foam pieces through the bronchoscope; however, this was not successful.

During the year, the patient required multiple admissions for management of chronic pulmonary sepsis due to recurrent fistula.

Successful closure of the persistent fistula was finally achieved three years later with the combination of endoscopic argon plasma coagulation and application of tiessel fibrin glue at the fistula opening through the gastroscope. The fistula has remained closed for two years.

\section{DISCUSSION}

Acquired gastropulmonary fistula is a rare complication of bariatric surgery and there are only two reported cases, one in the German literature (13) and one recent case in the English literature (4). An understanding of the pathogenesis is necessary for prevention and early recognition before it becomes serious. We believe that our patient developed an early contained leak from the gastrojejunal anastomosis that caused formation of an inflammatory phlegmon. Unfortunately, this was missed when the patient presented to her family doctor with complaints of new-onset mid back pain, and NSAIDs were prescribed for a 'pinched nerve'. The missed diagnosis and the problem not brought to the immediate attention of the referral out-of-town academic bariatric surgery unit, resulted in the delay of appropriate diagnostic and therapeutic care. The use of NSAIDs resulted in ulceration and significant upper gastrointestinal

\section{REFERENCES}

1. Schauer P, Ikramuddin S. Outcomes after laparoscopic Roux-en-Y gastric bypass for morbid obesity. Ann Surg 2000;23:515-29.

2. DeMaria E, Sugerman H, Schauer P, Harvey J. Results of 281 consecutive total laparascopic Roux-en-Y gastric bypasses to treat morbid obesity. Ann Surg 2002;2355:640-7.

3. Wittgrove A, Wesley C, Schubert R. Laparascopic gastric bypass, Roux en-Y: Technique and results in 75 patients with 3-30 months follow-up. Obes Surg 1996;6:500-4.

4. Campos J, Siqueira L, Ferraz A, Ferraz E. Gastrointestinal fistula after obesity surgery. J Am Coll Surg 2007;204:711-3.

5. Mehran A, Ukleja A, Szomstein S, Rosenthal R. Laparoscopic partial gastrectomy for the treatment of gastropleural fistula. JSLS 2005;92:213-5.

6. Khodov VD, Kharitonov VA. [Gastropleurobronchial fistula after a gunshot wound of the thorax and abdomen]. Klin Khir 1985;10:53-4.

7. Kalmar K, Molnar TF, Morgan A, Horvath OP. Non-malignant tracheo-gastric fistula following esophagectomy for cancer. Eur J Cardiothorac Surg 2000;183:363-5. bleeding. The inflammatory phlegmon from the contained leak subsequently eroded through the diaphragm into the lower lobe of the lung - setting up an inflammatory process resulting in fistulization that led to recurrent aspiration pneumonia and the formation of a lung abscess.

We believe that the combination of the inflammatory phlegmon in the upper abdomen from early contained anastomotic leak, erosion into the lung and formation of a lung abscess with attendant bronchiectasis and chronic sepsis, and distal stenosis at the Roux-en-Y reconstruction, resulted in the chronicity and recurrence of the fistula. The management was difficult; lobectomy was not advised due to the fear of producing more central gastric bronchial fistula and persistent postlobectomy space infection. We believe that if an early diagnosis of contained leak had been made with a water-soluble contrast study when the patient first complained of new onset back pain soon after the operation, definitive treatment with immediate percutaneous drainage of the infection, appropriate intravenous antibiotic and total parenteral nutrition could have prevented prolonged suffering and interventions.

The use of prolonged antibiotic therapy, withdrawal of all oral intake and total parenteral nutritional support can result in the successful management of the fistulous complication other than the type connecting with the lung parenchyma (12). However, the lack of success with conservative treatment was likely the result of the patient's lack of compliance by continuing to eat against medical advice.

The present case is unique because successful closure of the fistula was finally achieved from the gastric side using the combination of argon plasma coagulation to induce inflammatory fibrosis, and the subsequent application of tiessel fibrin glue, which makes it a novel technique for use in the future.

However, review of the literature has revealed a series of three patients (14), two with gastropleural fistula and one with gastroperitoneal fistula in whom complete closure was achieved by a combination of argon plasma coagulation, mechanical tissue excoriation and the injection of fibrin glue, and the application of multilayered vicryl mesh.

Laparoscopic Roux-en-Y gastric bypass has become the standard operation for morbid obesity and one must be vigilant about potential surgical complications. It would be prudent to perform a water-soluble contrast study with iohexol (Omnipaque, GE Healthcare, Canada) to assess the integrity of the anastomosis before starting oral intake.

8. Mussi A, Lucchi M, Davini F, Angeletti CA. Gastropleural fistula as complication of postpneumonectomy empyema. J Cardiovasc Surg (Torino) 2000;41:147-9.

9. O'Keefe PA, Goldstraw P. Gastropleural fistula following pulmonary resection. Thorax 1993;48:1278-9.

10. Kalmar K, Molnar TF, Morgan A, Horvath OP. Nonmalignant tracheogastric fistula following esophagectomy for cancer. Eur J Cardiothorac Surg 2000;183:363-5.

11. Markowitz AM, Herter FP. Gastropleural fistula as a complication of esophageal hiatal hernia. Ann Surg 1960;152:129-34.

12. Rotstein OD, Pruett TL, Simmons RL. Gastropleural fistula. Report of three cases and review of the literature. Am J Surg 1985;1503:392-6.

13. Trojan I, Imre J, Kulka F. [Gastro-pulmonary fistula as an unusual late complication of a hiatal hernia]. Thoraxchir Vask Chir 1971;19:152-4.

14. Fong D, Jajoo K, Piesman M, Lautz D. Endoscopic repair of gastropleural and gastroperitoneal fistulas with layered vicry and fibrin glue. Gastrointest Endosc 2007;655:275 (Abst). 


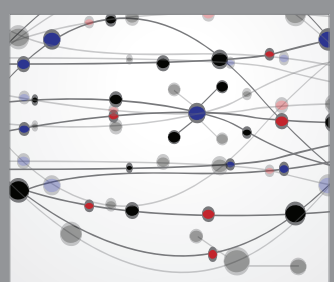

The Scientific World Journal
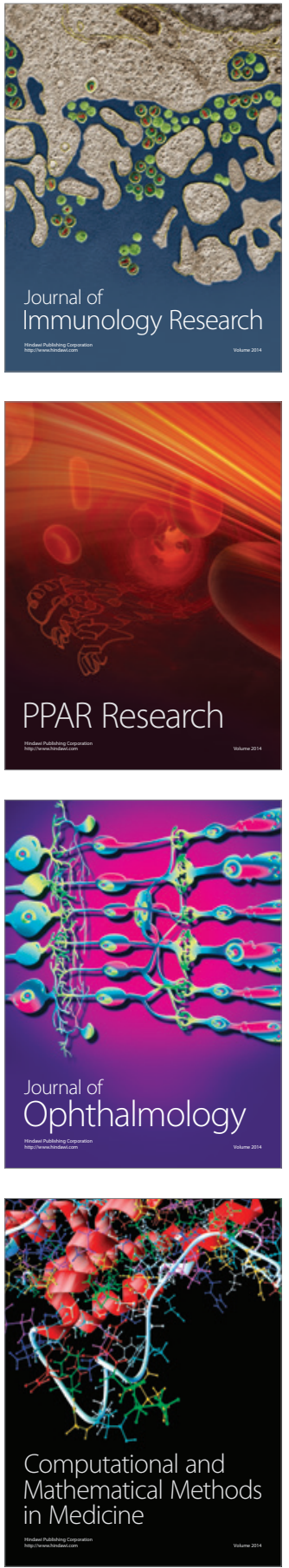

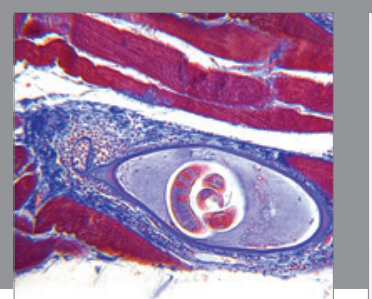

Gastroenterology Research and Practice

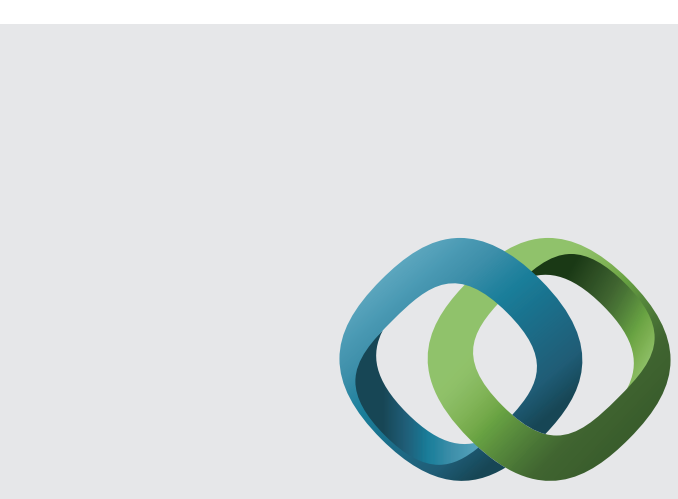

\section{Hindawi}

Submit your manuscripts at

http://www.hindawi.com
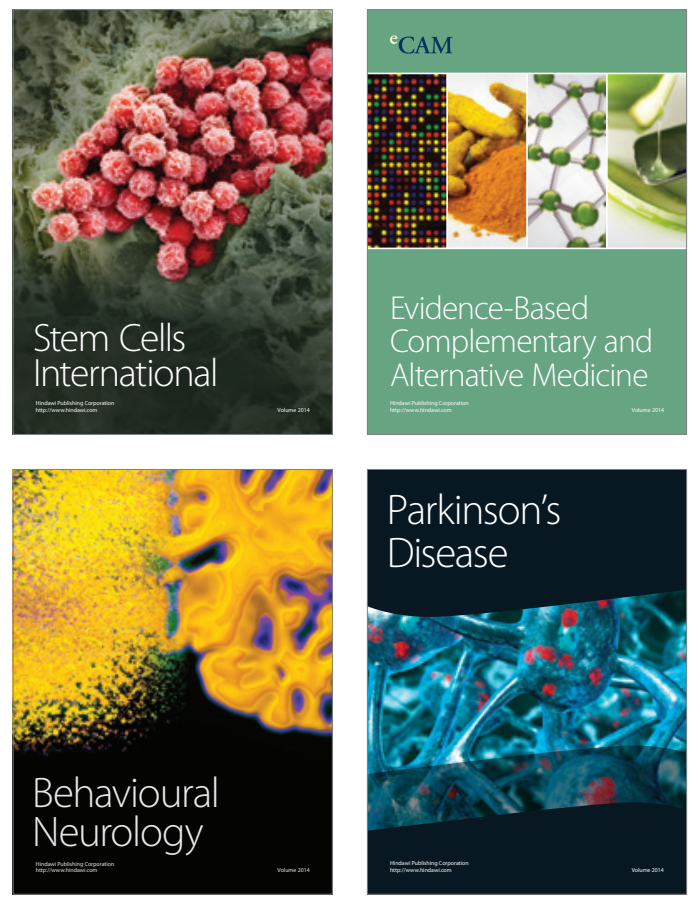
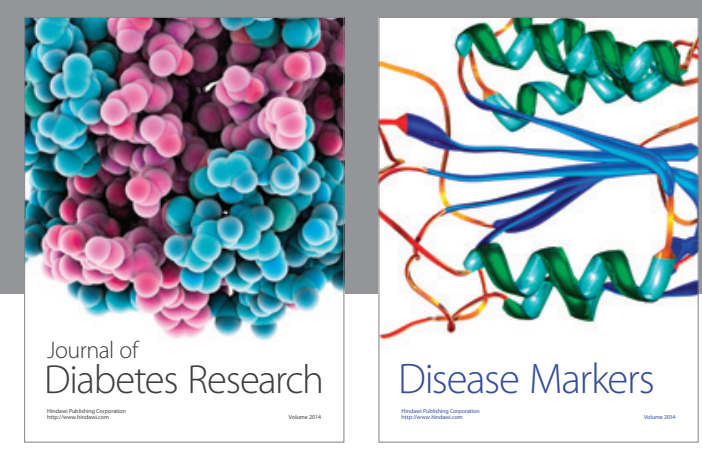

Disease Markers
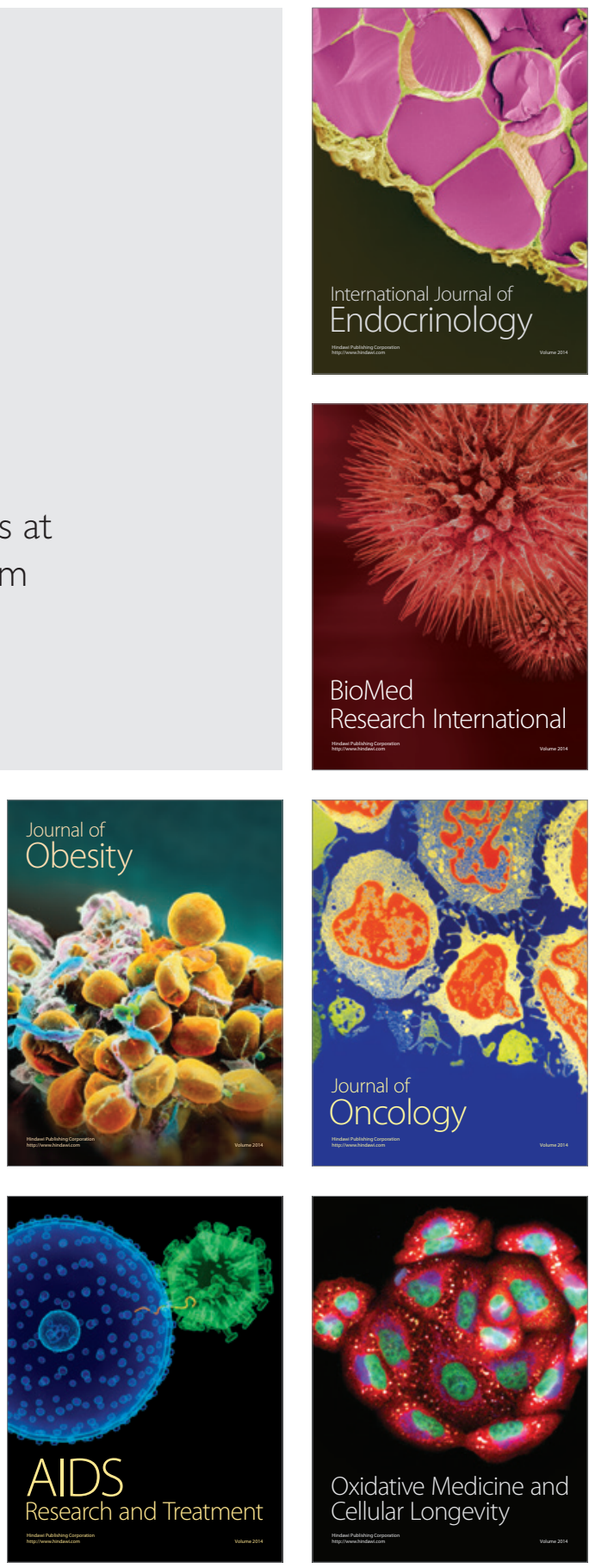